\title{
Research on Risk Evaluation of Large-scale Shopping Mall Based on Improved AHP Derived From EWM and TOPSIS
}

\author{
Yan Sen ${ }^{1, \text { a }}$, Wujing Tai ${ }^{2, *}$ \\ ${ }^{1}$ Safety Engineering Institute Shenyang, Aerospace University, Shenyang, China \\ ${ }^{2}$ Economy and management school, Shenyang Aerospace University, Shenyang, China \\ *wjt@sau.edu.cn
}

Keywords: AHP; TOPSIS; entropy weight method

\begin{abstract}
Because of its complex environment and intensive personnel, large shopping malls are very passive in their consequences and impact in the event of an accident. Therefore, in the aftermath of major shopping mall accidents, the government, large shopping malls, and victims all bear great economic pressure. Therefore, the purpose of this paper is to determine an effective safety evaluation system. Starting from the existing risks, the first 8 experts use the Analytic Hierarchy Process (AHP) to conduct safety evaluation analysis on general large-scale shopping malls, then apply TOPSIS analysis method and entropy weight method based on the results, and obtain the best expert judgment.
\end{abstract}

\section{Introduction}

In the previous risk analysis and safety evaluation of shopping malls, there are many methods used in AHP analysis. However, due to constraints imposed by experts' individual judgments, they may be inconsistent with the actual conditions of the shopping malls, and the evaluation contents are not accurate enough. The significance of this paper lies in proposing a method to improve AHP based on entropy weight method and TOPSIS method. It first uses AHP to evaluate the safety of general shopping malls, and then uses TOPSIS analysis method and entropy weight method to integrate evaluation according to the results. The weight of the optimal expert judgement, the study of this article not only can be carried out for the safety evaluation of the entire large-scale shopping mall industry, but also provides a basis for supervision of the management department, but also can gradually promote the application of this evaluation system model to other industries and public places..

\section{Risk Factors of Large-scalle Shopping Malls}

In general, the business system of large shopping malls is a dynamic system in space and time. Therefore, the risk factors in large shopping malls involve a wide range of complexities. From the 
perspective of systems theory such as security principles and system security, the factors affecting security can be attributed to people, machines, environment, and management. Therefore, it is very necessary to analyze the risks from the exterior, internal and security management of large-scale shopping malls.

\subsection{External risk}

The main categories are natural environment risks, surrounding environmental risks and construction risks. The construction risk is mainly the analysis of its construction structure, decoration materials, construction scale and construction of fire exits. The size of the building is directly related to the economic losses that may occur in the shopping mall. The larger the building size of the shopping mall, the more its assets, the greater the flow of people, the more complex the internal layout, and the greater the degree of difficulty in fighting fire fighting, which may occur. The casualties and property losses caused by the accident are correspondingly larger.

\subsection{Internal risk}

The main categories are fire risk, stampede risk, altitude drop risk, elevator risk, risk of door and window squeezing, and floor fall risk. For large shopping malls, preventing fire is a topic that will never be out of date.

\subsection{Security management risk}

Including safety management personnel risks, emergency plans and fire drills, safety education, firefighting facilities and equipment maintenance, safety monitoring centers, and safety management systems. Safety management is especially important for companies. It is about the production and development of companies..

\section{Establishment of Risk Assessment System}

\subsection{Introduction to Evaluation Methods}

The basic principle of the Analytic Hierarchy Process (AHP) is to decompose the problem into different compositional factors according to the nature of the problem and the overall goal to be achieved, and to aggregate the factors according to their interrelated influences and affiliation relationships according to different levels. A multi-level analysis of the structural model ultimately leads to the problem being determined at the lowest level (plans, measures for decision making, etc.) relative to the determination of the relative importance of the highest level (total goals) or relative priority ranking.

Entropy weight method is based on the accurate data of objective existence, the entropy algorithm is introduced into it, based on which the mathematical method for calculating the weight of each index is calculated. The entropy weight of each indicator reflects the amount of information mapped by the data in this indicator. Generally speaking, the greater the difference in data, the greater the amount of information reflected and the higher the relative weight.

The Topsis analysis method was first proposed by CLHwang and K. Yoon in 1981. The Topsis analysis method ranks a limited number of evaluation objects and the degree of closeness to idealized goals, and evaluates the relative merits of existing objects. The Topsis method is a sorting selection method that approximates the ideal solution. 
For the same sample, the evaluation results should not be very different, but in the actual evaluation process, because the principle of a single evaluation method is different, so the evaluation of the same research object often results in different evaluation As a result, sometimes even opposite conclusions are obtained. Therefore, before the combined evaluation, it is necessary to conduct a preliminary inspection, that is, a consistency test. In this paper, the consistency results of the weighted results of the two methods are tested according to the Kendall co-coefficient test.

\subsection{Establishment of safety evaluation index system for large-scale shopping malls}

- Establishment of risk assessment system

According to the risk analysis conducted by the shopping malls above, the risk assessment system established is shown in Figure 1.

\begin{tabular}{|c|c|c|}
\hline Target layer & Criteria layer & Plan layer \\
\hline 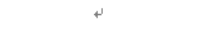 & \multirow{2}{*}{ Environmental risk B1 } & Natural environment risk: $\mathrm{Cl}$ \\
\hline 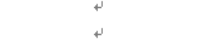 & & Environmental risk $\mathrm{C} 2$ \\
\hline 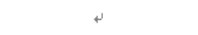 & \multirow{4}{*}{ Construction risk B2 } & building structure $\mathrm{C} 3$ \\
\hline 4 & & Decoration Materials $\mathrm{C}_{4}$ \\
\hline 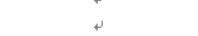 & & Construction scale $\mathrm{C} 5$ \\
\hline 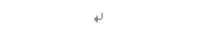 & & Fire exits $\mathrm{C} 6$ \\
\hline 4 & \multirow{7}{*}{$\begin{array}{c} \\
4 \\
4 \\
\text { Fire risk B3 }\end{array}$} & Electrical fire risk C $\mathrm{C}$ \\
\hline 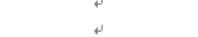 & & Maintenance fire risk C8 \\
\hline+ & & Catering fire risk $\mathrm{C} 9$ \\
\hline 4 & & Artificial fire risk $\mathrm{ClO}$ \\
\hline 4 & & Commodity own risk $\mathrm{C11}$ \\
\hline \multirow[t]{19}{*}{ Shopping mall risk factors $\mathrm{A}$} & & Natural causes $\mathrm{C} 12$ \\
\hline & & Fire facilities $\mathrm{C} 13$ \\
\hline & \multirow{3}{*}{ Stepping on risk B4 } & Emergency evacuation $\mathrm{C} 14$ \\
\hline & & Safety exit lighting $\mathrm{C} 15$ \\
\hline & & Emergencies $\mathrm{C} 16$ \\
\hline & \multirow{2}{*}{ Falling risk $B 5$} & Fence crash falling $\mathrm{C} 17$ \\
\hline & & Suspension falls C18 \\
\hline & \multirow{2}{*}{ Elevator risk B6 } & Elevator falling $\mathrm{C} 19$ \\
\hline & & machine malfunction $\mathrm{C} 20^{-3}$ \\
\hline & \multirow{2}{*}{ Door and window extrusion risk $B 7 \mathrm{P}$} & Daily evacuation $\mathrm{C} 21$ \\
\hline & & Door and window fallure $\mathrm{C} 22$ \\
\hline & \multirow{2}{*}{ Ground fall risk BS } & Personnel negligence $\mathrm{C} 23$ \\
\hline & & Weather natural causes $\mathrm{C} 24$ \\
\hline & \multirow{6}{*}{ Safety Management Risk Bg } & Security manager $\mathrm{C} 25$ \\
\hline & & Emergency plan and fire drill $\mathrm{C} 26$ \\
\hline & & safe eduction C27\% \\
\hline & & Facility maintenance $\mathrm{C} 28$ \\
\hline & & Security Monitoring Center C 29 \\
\hline & & Safety Management System $\mathrm{C} 30$ \\
\hline
\end{tabular}

Figure 1 Shopping mall risk assessment system table

In combination with the method described above, this paper invites eight experts to score points. The AHP judgment matrix and the weights determined according to the scores of experts are acceptable, and the weights of the criteria layer and the weights of the plan layers can be obtained.

- $\quad$ Entropy Weight Determination of Weights

Taking the weight of the criterion level as an example, the weights are calculated using the entropy method, and the sum of the weight of each indicator of each expert and the weight obtained from the entropy method based on the weight value is taken as its comprehensive evaluation value. The criteria layer evaluation values are shown in Table 1.

Based on Table 1, the comprehensive evaluation value of the scheme layer can be obtained by the same reason, shown in Table 2. 


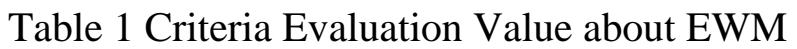

\begin{tabular}{|c|c|}
\hline 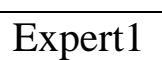 & 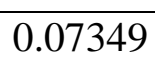 \\
\hline 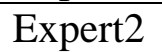 & 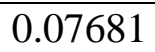 \\
\hline 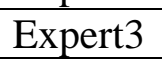 & 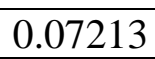 \\
\hline 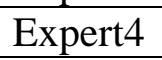 & 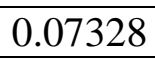 \\
\hline 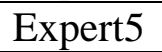 & 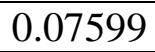 \\
\hline 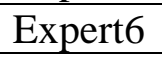 & 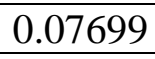 \\
\hline 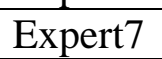 & 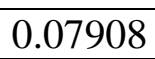 \\
\hline 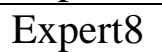 & 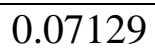 \\
\hline
\end{tabular}

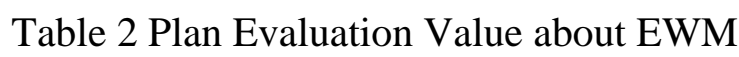

\begin{tabular}{|c|c|}
\hline 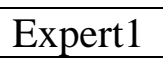 & 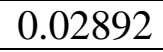 \\
\hline 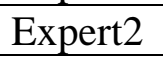 & 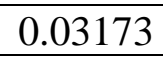 \\
\hline 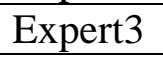 & 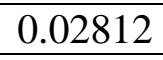 \\
\hline 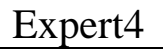 & 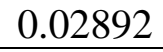 \\
\hline 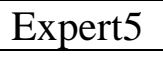 & 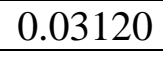 \\
\hline 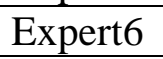 & 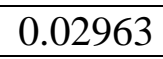 \\
\hline 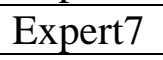 & 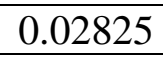 \\
\hline 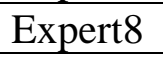 & 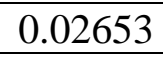 \\
\hline
\end{tabular}

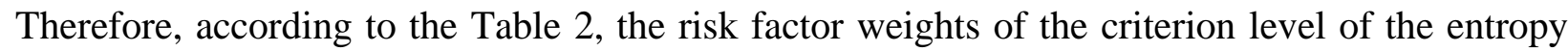

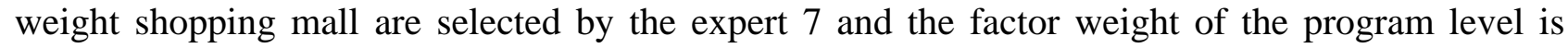

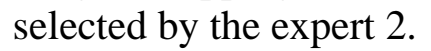

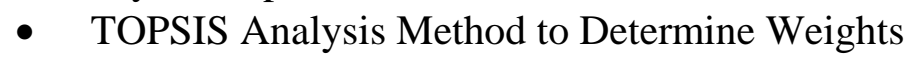

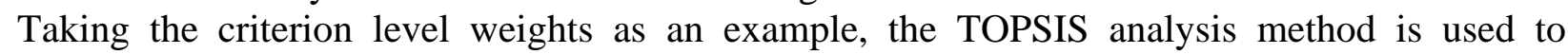

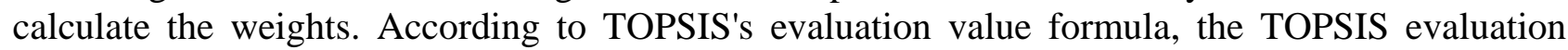

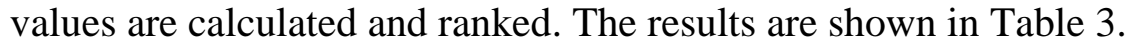

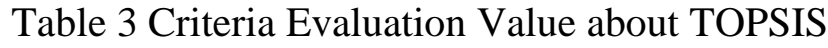

\begin{tabular}{|c|c|}
\hline 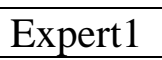 & 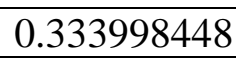 \\
\hline 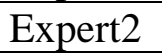 & 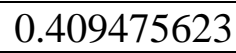 \\
\hline 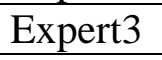 & 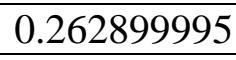 \\
\hline 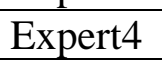 & 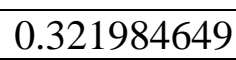 \\
\hline 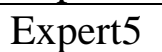 & 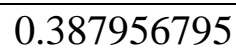 \\
\hline 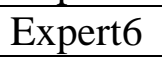 & 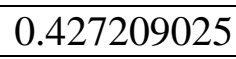 \\
\hline 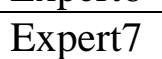 & 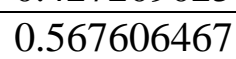 \\
\hline 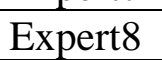 & 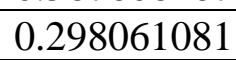 \\
\hline
\end{tabular}

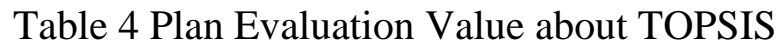

\begin{tabular}{|c|c|}
\hline 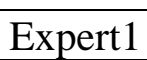 & 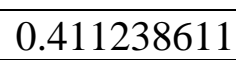 \\
\hline 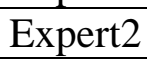 & 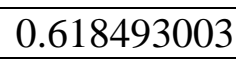 \\
\hline 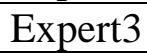 & 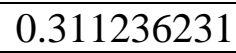 \\
\hline 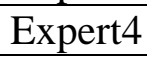 & 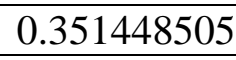 \\
\hline 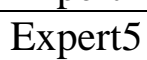 & 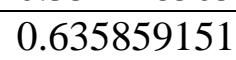 \\
\hline 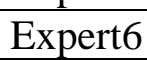 & 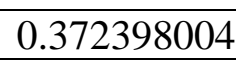 \\
\hline 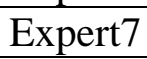 & 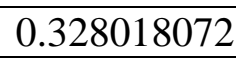 \\
\hline 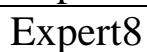 & 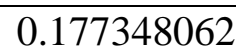 \\
\hline
\end{tabular}




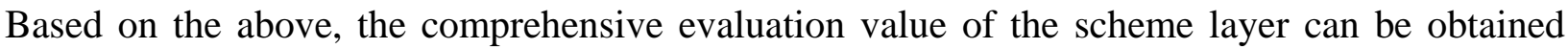

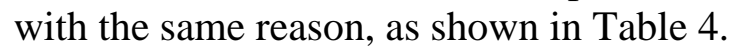

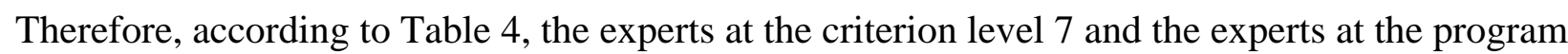

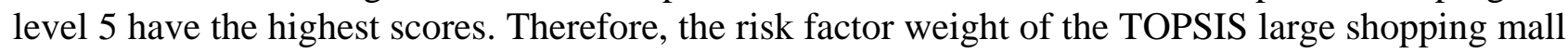

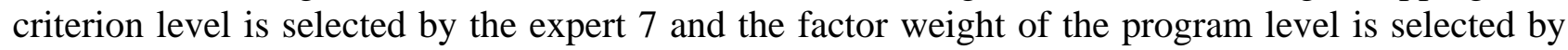

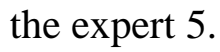

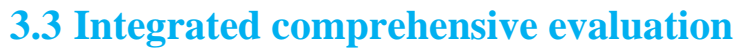

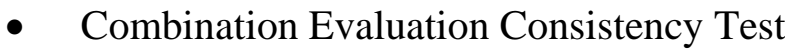

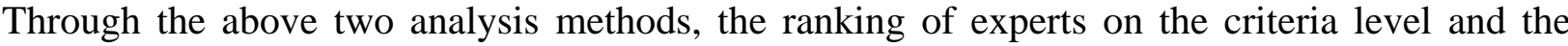

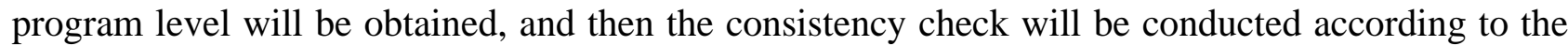

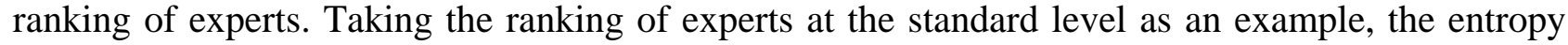

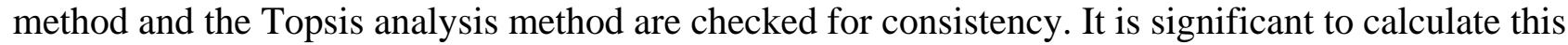

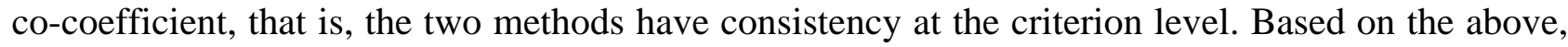

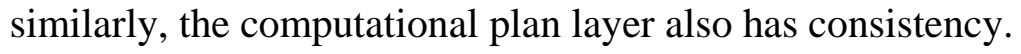

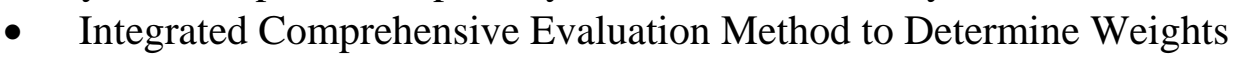

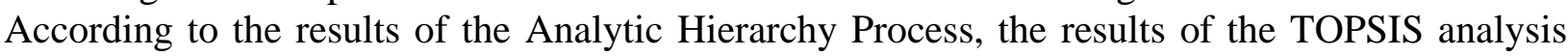

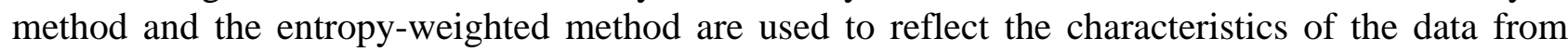

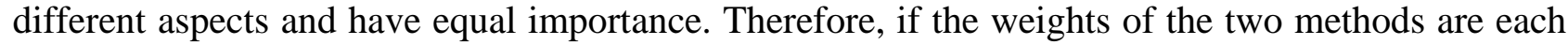

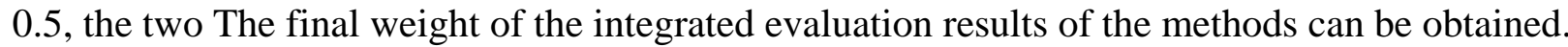

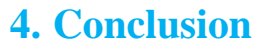

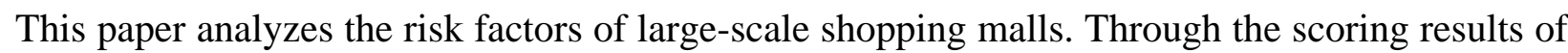

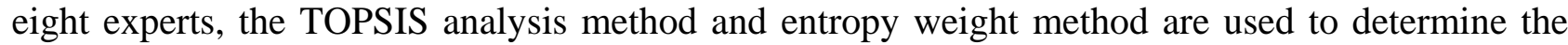

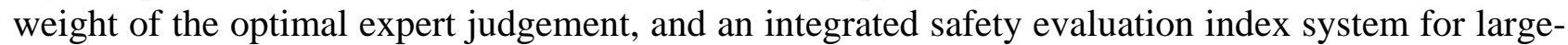

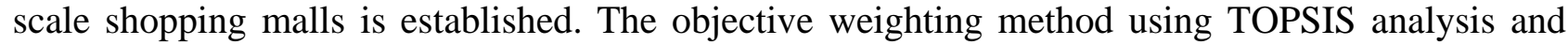

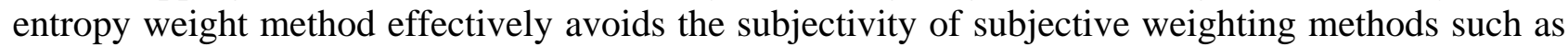

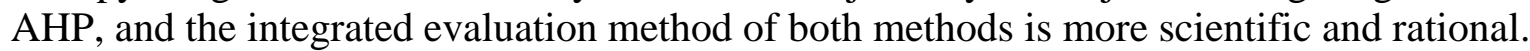

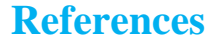

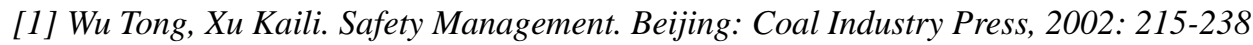

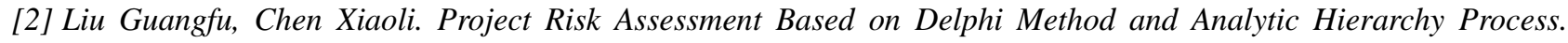

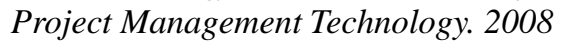

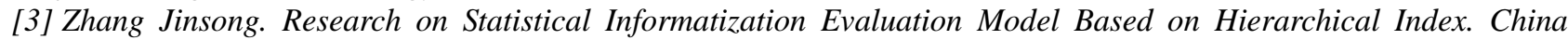

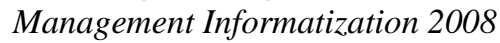

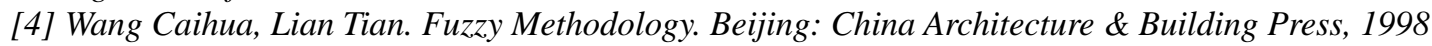

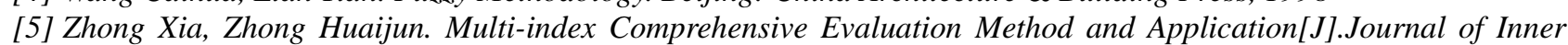

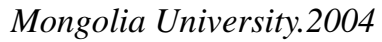

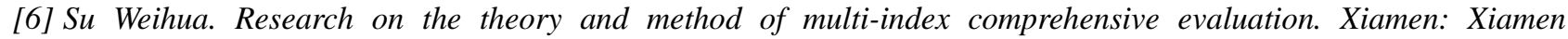

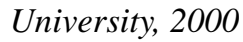

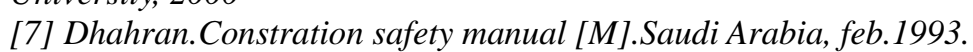

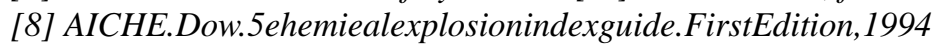

